\title{
CAPACIDAD ANTIOXIDANTE DE EXTRACTOS OBTENIDOS DE LAS HOJAS DE Senecio rufescens DC
}

\author{
Enrique Javier Aguilar Felices ${ }^{*}$, Pablo Enrique Bonilla Rivera ${ }^{\mathrm{b}}$, \\ Edwin Carlos Enciso Roca ${ }^{a}$,
}

\begin{abstract}
RESUMEN
Senecio rufescens DC es una planta altoandina utilizada tradicionalmente para tratar problemas del "mal de altura" y de dolencias gastrointestinales. En el proceso de adaptación a condiciones extremas, desarrolló su capacidad para biosintetizar metabolitos secundarios de gran importancia terapéutica como son los compuestos fenólicos. Por tanto, esta investigación se desarrolló con el objetivo de determinar el contenido de fenoles totales, flavonoides, flavonoles y la capacidad antioxidante del extracto metanólico de las hojas y de sus fracciones de $n$ - hexano, diclorometano, acetato de etilo y metanólica, respectivamente. La fracción metanólica, mostró el mayor contenido de fenoles totales (149,81 $\pm 5,02 \mathrm{GAE} / \mathrm{g}$ de extracto), flavonoides $(47,33 \pm 2,27 \mathrm{QE} / \mathrm{g}$ de extracto) y flavonoles $(14,34 \pm 0,69 \mathrm{QE} / \mathrm{g}$ de extracto) (p $<0,05)$, respectivamente, mientras que su capacidad antioxidante $(529,80 \pm 14,30 ; 444,38 \pm$ 11,$31 ; 406,86 \pm 24,58 \mu$ moles ET/g de extracto, para los ensayos de DPPH, ABTS y FRAP, respectivamente) fue superior a las otras fracciones $(p<0,05)$. Se concluye que la fracción metanólica del extracto metanólico, demostró poseer un alto contenido de fenoles totales, flavonoides y flavonoles, así como, una alta capacidad antioxidante, respectivamente.
\end{abstract}

Palabras clave: Senecio rufescens DC., compuestos fenólicos, capacidad antioxidante.

\section{ANTIOXIDANT CAPACITY OF EXTRACTS OBTAINED FROM LEAVES OF Senecio rufescens DC.}

\begin{abstract}
Senecio rufescens DC. is a South American Andean plant traditionally used to treat "altitude sickness" and gastrointestinal ailments. In the process of adaptation to extreme conditions, it developed its ability to biosynthesize secondary metabolites of great therapeutic importance such as phenolic compounds. Therefore, this research was developed with the objective

\footnotetext{
${ }^{a}$ Facultad de Ciencias de la Salud, Universidad Nacional de San Cristóbal de Huamanga, Av. Independencia s/n Ciudad Universitaria, Ayacucho, Perú,

*enrique.aguilar@unsch.edu.pe

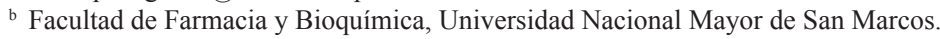


of determining of total phenols, flavonoids, flavonols and the antioxidant capacity of the methanolic extract of the leaves and its fractions of $n$ - hexane, dichloromethane, ethyl acetate and methanolic, respectively. The methanolic fraction showed the highest content of total phenols $(149,81 \pm 5,02 \mathrm{GAE} / \mathrm{g}$ of extract), flavonoids $(47,33 \pm 2,27 \mathrm{QE} / \mathrm{g}$ of extract) and flavonols $(14,34 \pm 0,69 \mathrm{QE} / \mathrm{g}$ of extract) $(\mathrm{p}<0,05)$, while, its antioxidant capacity $(529,80$ $\pm 14,30 ; 444,38 \pm 11,31 ; 406,86 \pm 24,58 \mu$ moles ET/g of extract, for the DPPH, ABTS and FRAP tests, respectively) was higher than the other fractions $(p<0,05)$. It is concluded that the methanolic fraction of the methanolic extract was shown to have a high content of total phenols, flavonoids and flavonols, as well as a high antioxidant capacity, respectively.

Key words: Senecio rufescens DC., phenolic compounds, antioxidant capacity.

\section{INTRODUCCIÓN}

El género Senecio, es uno de los géneros más diversos de la familia Astearaceae con más de 1500 especies y en el Perú se han reportado 177 especies con distribución restringida, consideradas como endémicas y adaptadas a altitudes superiores a $4000 \mathrm{msnm}^{1}$. Se caracterizan por tener en su composición química monoterpenos, diterpenos, sesquiterpenos, triterpenoides, esteroides, flavonoides, cumarinas, ácidos fenólicos y alcaloides ${ }^{2}$. Se ha reportado que extractos obtenidos de las partes aéreas de otras especies de Senecio tienen actividad antioxidante, en las cuales se hicieron responsables de dicha actividad a los compuestos fenólicos ${ }^{3,4,5}$.

S. rufescens DC, es un arbusto erguido de $40-70 \mathrm{~cm}$ de altura, parcialmente caducifolio hacia la base, tallos densamente hojosos hacia el ápice; hojas sésiles, dispuestas en fascículos laterales, lineares a linear - lanceoladas, enteras, márgenes conspicuamente resolutas, densamente glanduloso - pubescente en ambas caras, de 2 a $3 \mathrm{~cm}$ de longitud por 1,5 a $3 \mathrm{~mm}$ de ancho; inflorescencias en cabezuelas discoideas, solitarias, en el ápice de las ramas laterales; involucro acampanulado de $8-10 \mathrm{~mm}$ de largo por $10 \mathrm{~mm}$ de diámetro; brácteas involucrales lineal - lanceoladas, glandulosas, pubescentes en el dorso; flores isomorfas, hermafroditas; corola tubulosa, amarillento - parduzco, pentalobulada, fruto aquenio cilíndrico, con numerosas cerdas o pelos blancos ${ }^{6}$. Su adaptación a la altitud, se debe a su capacidad de tolerar el estrés biótico y abiótico, tales como, salinidad, radiación solar, temperaturas extremas, sequías y para hacer frente a sus depredadores, para el cual biosintetizan compuestos fenólicos, alcaloides y otros compuestos como mecanismos de adaptación y defensa ${ }^{7}$. Tradicionalmente es utilizada para dolencias estomacales y el "mal de altura"6.

La búsqueda de antioxidantes de origen vegetal es una preocupación permanente en la actualidad, para así poder prevenir y controlar a las enfermedades relacionadas al estrés oxidativo, tales como el envejecimiento celular, enfermedades degenerativas, diabetes, y cáncer ${ }^{4}$. 
En el Perú, se han realizado pocos estudios sobre el contenido de compuestos fenólicos ${ }^{8}$ y capacidad antioxidante en especies endémicas del género Senecio, en particular no existen reportes para $S$. rufescens DC, el cual nos motivó a realizar esta investigación con el objetivo de determinar: el contenido de fenoles totales, flavonoides y flavonoles; y su capacidad antioxidante utilizando los ensayos de DPPH, ABTS y FRAP del extracto metanólico de las hojas de $S$. rufescens DC., y de sus fracciones de $n$ - hexano, diclorometano, acetato de etilo y metanólico, respectivamente.

\section{PARTE EXPERIMENTAL}

\section{Muestra vegetal}

Un kilogramo de hojas frescas de $S$. rufescens DC. fueron recolectadas en el distrito de Paras, provincia de Cangallo (Ayacucho - Perú) a una altura de $4756 \mathrm{msnm}$, la localización exacta fue longitud - 74,74177187188302 y latitud -13,358120254734844. La especie fue certificada por el Mg. Hamilton Beltrán del Museo de Historia Natural de la Universidad Nacional Mayor de San Marcos, dejándose una muestra en dicha institución.

\section{Preparación de la muestra}

Las hojas fueron desecadas a la sombra hasta sequedad, después fueron triturados utilizando una licuadora hasta obtener un polvo fino y conservado en refrigeración en un frasco ámbar hasta su uso.

\section{Obtención del extracto metanólico}

$100 \mathrm{~g}$ de muestra pulverizada desecada fue extraída con dos litros de metanol (4 x $500 \mathrm{~mL})$ por maceración dinámica durante cuatro horas utilizando un agitador magnético, se filtró el extracto, se reunieron los filtrados y se concentraron en un evaporador rotatorio hasta sequedad, obteniéndose un extracto seco, que fue conservado en refrigeración a $4{ }^{\circ} \mathrm{C}$, hasta su posterior uso. Se pesó el extracto y se determinó el porcentaje de rendimiento en relación a $100 \mathrm{~g}$ de muestra seca en polvo.

\section{Fraccionamiento del extracto metanólico por cromatografía en columna}

Una columna cromatográfica de vidrio $(1,5 \mathrm{~cm}$ x $60 \mathrm{~cm})$ fue empacada con $25 \mathrm{~g}$ de silica gel 60 para columna cromatográfica $\left(70-230\right.$ mesh, Merck $\left.{ }^{\circledR}\right)$ y eluída con $n$ - hexano. 5 g del extracto metanólico se mezcló con silica gel y se añadió a la columna cromatográfica. Seguidamente se realizaron eluciones sucesivas con $100 \mathrm{~mL}$ de $n$ - hexano, diclorometano, acetato de etilo y metanol, respectivamente. Se colectó cada una de las fracciones y se evaporó a sequedad en un evaporador rotatorio hasta obtener un extracto seco; y conservados en refrigeración a $4{ }^{\circ} \mathrm{C}$ hasta su uso. Se pesó cada uno de los extractos y se determinó el porcentaje de rendimiento en relación a $5 \mathrm{~g}$ de extracto metanólico utilizado para el fraccionamiento. 


\section{Determinación del contenido de fenoles totales}

Se utilizó el método del reactivo Folin - Ciocalteu ${ }^{9}$. La muestra se preparó a la concentración de $1 \mathrm{mg} / \mathrm{mL}$ en metanol. $150 \mu \mathrm{L}$ de la muestra fue mezclada con $150 \mu \mathrm{L}$ del reactivo de Folin - Ciocalteu (Merck ${ }^{\circledR}$ ) 0,25 N; $2400 \mu \mathrm{L}$ de agua destilada, se mezcló por 5 min y se dejó en reposo por 3 min. Luego se añadió $300 \mu \mathrm{L}$ de solución de carbonato de sodio $1 \mathrm{~N}$. La mezcla fue incubada en la oscuridad por $2 \mathrm{~h}$ a temperatura ambiente. La absorbancia fue leída a $725 \mathrm{~nm}$ (Espectrofotómetro UV - Vis GENESYS 150 - THERMO SCIENTIFIC), contra un blanco de reacción. Una curva de calibración fue preparada con ácido gálico $(0,0$; $5,0 ; 10,0 ; 15,0 ; 20,0 ; 25,0 ; 30,0 \mu \mathrm{g} / \mathrm{mL})$. Todos los ensayos fueron realizados por triplicado. El contenido de fenoles totales fue expresado como mg equivalentes de ácido gálico por $\mathrm{g}$ de extracto (mg GAE/g de extracto)

\section{Determinación del contenido de flavonoides}

Se realizó según el método descrito por Zhishen y col. ${ }^{10}$, con ligeras modificaciones. La muestra se preparó a la concentración de $1 \mathrm{mg} / \mathrm{mL}$. En un tubo de ensayo, se mezcló 500 $\mu \mathrm{L}$ del extracto con $500 \mu \mathrm{L}$ de agua destilada y $150 \mu \mathrm{L}$ de nitrito de sodio al $5 \%$. Después de $5 \mathrm{~min}$, se adicionó $150 \mu \mathrm{L}$ de cloruro de aluminio al $10 \%$. Luego de $6 \mathrm{~min}, 2 \mathrm{~mL}$ de hidróxido de sodio al $4 \%$ se adicionó a la mezcla. Finalmente, se completó hasta $5 \mathrm{~mL}$ con agua destilada y se mezcló bien en un vortex; y se dejó en reposo por 15 min a temperatura ambiente en ausencia de luz. La absorbancia fue leída a $510 \mathrm{~nm}$ (Espectrofotómetro UV Vis GENESYS 150 - THERMO SCIENTIFIC), contra un blanco de reacción. Una curva de calibración fue preparada con quercetina $(40,0 ; 80,0 ; 120,0 ; 160,0 ; 200,0 \mu \mathrm{g} / \mathrm{mL})$. Todos los ensayos fueron realizados por triplicado. El contenido de flavonoides fue expresado como $\mathrm{mg}$ equivalentes de quercetina por $\mathrm{g}$ de extracto ( $\mathrm{mg} \mathrm{QE} / \mathrm{g}$ de extracto).

\section{Determinación del contenido de flavonoles}

Se determinó por el método descrito por Miliauskas y col. ${ }^{11}$. La muestra se preparó a la concentración de $1 \mathrm{mg} / \mathrm{mL}$. $500 \mu \mathrm{L}$ del extracto fue mezclado con $1 \mathrm{~mL}$ de cloruro de aluminio al $4 \%$ y $3 \mathrm{~mL}$ de acetato de sodio al $5 \%$. La mezcla se dejó en reposo por 2,5 horas a $20^{\circ} \mathrm{C}$. La absorbancia fue leída a $440 \mathrm{~nm}$ (Espectrofotómetro UV - Vis GENESYS 150 THERMO SCIENTIFIC), contra un blanco de reacción. Se preparó una curva de calibración con quercetina $(0,0 ; 4,0 ; 6,0 ; 8,0 ; 16,0 ; 20,0 \mu \mathrm{g} / \mathrm{mL})$. Todos los ensayos fueron realizados por triplicado. El contenido de flavonoles fue expresado como $\mathrm{mg}$ equivalentes de quercetina por $\mathrm{g}$ de extracto (mg QE/g de extracto).

\section{Determinación de actividad antioxidante por método de secuestramiento del radical libre 1,1 - difenil - picril - hidrazilo (DPPH)}

Se desarrolló el procedimiento descrito por Brand - Williams y col., modificado por Thaipong y col., ${ }^{9}$ y ajustada a las condiciones de nuestro laboratorio. La muestra se preparó a la concentración de $1 \mathrm{mg} / \mathrm{mL}$. Se preparó una solución stock del radical libre DPPH de 20 $\mathrm{mg} / \mathrm{L}$ en metanol. Se midió la absorbancia a $517 \mathrm{~nm}$ y se ajustó a $0,7 \pm 0,2$ con metanol. Se midió $500 \mu \mathrm{L}$ del extracto y se adicionó a $2000 \mu \mathrm{L}$ de la solución del DPPH y se mezcló en un vortex. La mezcla fue incubada en la oscuridad por 30 min y la absorbancia fue leída a 517 
nm (Espectrofotómetro UV - Vis GENESYS 150 - THERMO SCIENTIFIC). El porcentaje de la actividad secuestradora del radical libre se calculó de acuerdo a la siguiente relación:

$$
\% \text { de actividad secuestradora del DPPH }=\left[\frac{\mathrm{A}_{\mathrm{DPPH}}-\mathrm{A}_{\mathrm{MP}}}{\mathrm{A}_{\mathrm{DPPH}}}\right] \times 100
$$

En donde ADPPH y AMP corresponden a las absorbancias del DPPH, muestra problema tratada con DPPH, respectivamente.

Asimismo, se preparó una curva estándar con Trolox $(25$ - $800 \mu$ moles $)$ y los resultados fueron expresados como $\mu$ moles equivalentes a Trolox por gramo de extracto $(\mu \mathrm{mol} \mathrm{ET} / \mathrm{g}$ de extracto).

Determinación de actividad antioxidante por el método de secuestramiento del catión radical del ácido 2,2'- azinobis - (3 - etilbenzotiazolina) - 6 - sulfónico (ABTS ${ }^{\bullet+}$ )

Se utilizó el protocolo descrito por Arnao y col., modificado por Thaipong y col${ }^{9}$. La muestra se preparó a la concentración de $1 \mathrm{mg} / \mathrm{mL}$ en metanol. La solución patrón (SP), estuvo constituida por 7,4 mM de ABTS y 2,6 mM de persulfato de potasio. La solución de trabajo (ST) se preparó a partir de $1 \mathrm{~mL}$ de SP disuelto en metanol y se ajustó la absorbancia a 1,1 \pm 0,02 diluyendo con metanol a la longitud de onda de $734 \mathrm{~nm}$ (Espectrofotómetro UV - Vis GENESYS 150 - THERMO SCIENTIFIC). $150 \mu \mathrm{L}$ de la muestra fue mezclado con $2850 \mu \mathrm{L}$ de solución de ABTS•+ y se dejó en la oscuridad por $2 \mathrm{~h}$ y la absorbancia fue leída a $734 \mathrm{~nm}$. Se calculó el porcentaje de captación del radical libre utilizando la siguiente ecuación:

$$
\% \text { de actividad secuestradora del } \mathrm{ABTS}=\left[\frac{\mathrm{A}_{\mathrm{ABTS}}-\mathrm{A}_{\mathrm{MP}}}{\mathrm{A}_{\mathrm{ABTS}}}\right] \times 100
$$

En donde AABTS y AMP corresponden a las absorbancias del ABTS •+ y la muestra problema tratada con $\mathrm{ABTS}^{\bullet+}$, respectivamente.

Asimismo, se preparó una curva estándar con Trolox $(25-600 \mu$ moles $)$. Los resultados fueron expresados como $\mu$ moles equivalentes de Trolox por g de extracto $(\mu \mathrm{mol}$ ET/g de extracto).

Determinación de actividad antioxidante por el método de reducción de hierro (FRAP) Se aplicó el procedimiento descrito por Benzie y Strain modificada por Thaipong y col$^{9}$. La muestra se preparó a la concentración de $1 \mathrm{mg} / \mathrm{mL}$ en metanol. La solución patrón incluyó $300 \mathrm{mM}$ de buffer acetato $\mathrm{pH}$ 3,6; $10 \mathrm{mM} \mathrm{TPTZ} \mathrm{(2,} \mathrm{4,} \mathrm{6} \mathrm{-} \mathrm{tripiridil} \mathrm{-} \mathrm{triazina)} \mathrm{disuelto} \mathrm{en} \mathrm{una}$ solución de $\mathrm{HCl} 40 \mathrm{mM}$ y $20 \mathrm{mM}$ de solución de $\mathrm{FeCl} 3$ en agua. La solución de trabajo (ST) se obtuvo mezclando $25 \mathrm{~mL}$ de buffer acetato, $2,5 \mathrm{~mL}$ de solución de TPTZ y 2,5 $\mathrm{mL}$ de la solución de $\mathrm{FeCl} 3$, la misma que fue calentada a $37^{\circ} \mathrm{C}$ antes de su uso. $150 \mu \mathrm{L}$ de muestra fue mezclada con $2850 \mu \mathrm{L}$ de solución ST y se dejó en reposo por 30 minutos; y la absorbancia fue leída a $593 \mathrm{~nm}$ (Espectrofotómetro UV - Vis GENESYS 150 - THERMO SCIENTIFIC). Una curva estándar fue preparada con Trolox $(25$ - $800 \mu$ moles $)$. Los resultados fueron expresados como $\mu$ moles equivalentes de Trolox por g de extracto ( $\mu$ moles ET/g de extracto) 


\section{Análisis de datos}

En la determinación del contenido de compuestos fenólicos, flavonoides, flavonoles y la capacidad antioxidante por los métodos del DPPH, ABTS y FRAP, los resultados fueron expresados como la media \pm desviación estándar de tres repeticiones. El análisis de varianza y la prueba de comparaciones múltiples de Scheffe fueron utilizados para demostrar las diferencias significativas entre los extractos con un nivel de significancia de $p<0,05$.

\section{RESULTADOS Y DISCUSIÓN}

Tabla 1. Rendimiento del extracto metanólico de las hojas de S. rufescens DC. y de sus fracciones.

\begin{tabular}{lccc}
\hline Extracto y/o fracción & $\begin{array}{c}\text { Peso de } \\
\text { muestra }(\mathrm{g})\end{array}$ & $\begin{array}{c}\text { Peso seco de extracto } \\
\text { y/o fracción }(\mathrm{g})\end{array}$ & $\begin{array}{c}\text { Porcentaje de } \\
\text { rendimiento (\%) }\end{array}$ \\
\hline Extracto metanólico & 100 & 40 & 40,00 \\
Fracción de $n$ - hexano & 5 & 0,66 & 14,18 \\
Fracción de diclorometano & 5 & 1,85 & 39,79 \\
Fracción de acetato de etilo & 5 & 0,86 & 18,52 \\
Fracción metanólica & 5 & 1,28 & 27,51 \\
\hline
\end{tabular}

Tabla 2. Contenido de fenoles totales, flavonoides y flavonoles del extracto metanólico de $S$. rufescens DC. y de sus fracciones.

\begin{tabular}{|c|c|c|c|c|c|}
\hline \multirow[b]{2}{*}{$\begin{array}{l}\text { Extracto/ } \\
\text { Fracción }\end{array}$} & \multirow{2}{*}{$\begin{array}{c}\text { Fenoles } \\
\text { totales } \\
\text { (mg GAE/g } \\
\text { de extracto) }\end{array}$} & \multirow{2}{*}{$\begin{array}{c}\text { Flavonoides } \\
\text { (mg QE/g } \\
\text { de extracto) }\end{array}$} & \multirow{2}{*}{$\begin{array}{c}\text { Flavonoles } \\
\text { (mg QE/g } \\
\text { de extracto) }\end{array}$} & \multicolumn{2}{|c|}{ Relación } \\
\hline & & & & $\begin{array}{c}\text { Flavonoides } \\
/ \\
\text { Fenoles } \\
\text { totales }\end{array}$ & $\begin{array}{l}\text { Flavonoles/ } \\
\text { flavonoides }\end{array}$ \\
\hline $\begin{array}{l}\text { Extracto } \\
\text { Metanólico }\end{array}$ & $64,5 \pm 1,17^{b}$ & $\begin{array}{c}36,55 \pm \\
1,91^{\mathrm{c}}\end{array}$ & $\begin{array}{c}10,58 \pm \\
0,85^{\mathrm{c}}\end{array}$ & 0,57 & 0,29 \\
\hline $\begin{array}{l}\text { Fracción de } \\
n \text {-hexano }\end{array}$ & N.D. & N.D. & N.D. & & \\
\hline $\begin{array}{l}\text { Fracción } \\
\text { Diclorometano } \\
\text { Fracción de }\end{array}$ & $44,32 \pm 1,6^{\mathrm{a}}$ & $\begin{array}{c}17,27 \pm \\
1,64^{\mathrm{a}}\end{array}$ & $6,48 \pm 0,34^{b}$ & 0,39 & 0,38 \\
\hline $\begin{array}{l}\text { Acetato de } \\
\text { etilo }\end{array}$ & $74,46 \pm 1,6^{c}$ & $28,06 \pm 1,1^{\mathrm{b}}$ & $2,92 \pm 0,23^{\mathrm{a}}$ & 0,38 & 0,1 \\
\hline 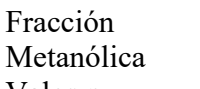 & $\begin{array}{c}149,81 \pm \\
5,02^{\mathrm{d}}\end{array}$ & $\begin{array}{c}47,33 \pm \\
2,27^{\mathrm{d}}\end{array}$ & $\begin{array}{c}14,34 \pm \\
0,69^{d}\end{array}$ & 0,32 & 0,3 \\
\hline Valor $p$ & $<0,05$ & $<0,05$ & $<0,05$ & & \\
\hline
\end{tabular}

Los resultados son el promedio \pm D.E. de tres determinaciones, las letras con superíndices diferentes significan diferencias significativas $(p<0,05)$. 
Tabla 3. Capacidad antioxidante del extracto metanólico de las hojas de S. rufescens DC. y de sus fracciones.

\begin{tabular}{|c|c|c|c|c|c|}
\hline \multirow{2}{*}{$\begin{array}{l}\text { Extracto/ } \\
\text { Fracción }\end{array}$} & \multicolumn{2}{|c|}{ DPPH } & \multicolumn{2}{|c|}{ ABTS } & \multirow{2}{*}{$\begin{array}{c}\text { FRAP } \\
(\mu \text { moles } \\
\text { ET/g de } \\
\text { muestra) }\end{array}$} \\
\hline & $\%$ & $\begin{array}{l}\mu \text { moles ET/g } \\
\text { de muestra }\end{array}$ & $\%$ & $\begin{array}{c}\mu \text { moles ET/g } \\
\text { de muestra }\end{array}$ & \\
\hline Extracto & $13,61 \pm$ & $76,97 \pm$ & $27 \pm$ & $172,38 \pm$ & $188,68 \pm$ \\
\hline Metanólico & $0,84^{\mathrm{b}}$ & $7,17^{\mathrm{b}}$ & $1,57^{\mathrm{b}}$ & $10,78^{b}$ & $2,76^{\mathrm{b}}$ \\
\hline $\begin{array}{l}\text { Fracción } \\
n \text { - hexano }\end{array}$ & $\begin{array}{c}2,66 \pm \\
0,93^{\mathrm{a}}\end{array}$ & $0^{\mathrm{a}}$ & $\begin{array}{c}15,28 \pm \\
1,51^{\mathrm{a}}\end{array}$ & $\begin{array}{c}91,71 \pm \\
10,42^{\mathrm{a}}\end{array}$ & $\begin{array}{c}160,8 \pm \\
1,66^{\mathrm{ab}}\end{array}$ \\
\hline $\begin{array}{l}\text { Fracción } \\
\text { Diclorometano }\end{array}$ & $\begin{array}{c}3,96 \pm \\
0,47^{\mathrm{a}}\end{array}$ & $0^{\mathrm{a}}$ & $\begin{array}{c}14,44 \pm \\
0,58^{\mathrm{a}}\end{array}$ & $85,93 \pm 4^{\mathrm{a}}$ & $\begin{array}{c}124,89 \pm \\
0,17^{\mathrm{a}}\end{array}$ \\
\hline $\begin{array}{l}\text { Fracción } \\
\text { Acetato de } \\
\text { etilo }\end{array}$ & $\begin{array}{c}23,27 \pm \\
3,41^{\mathrm{c}}\end{array}$ & $\begin{array}{c}159,82 \pm \\
29,24^{\mathrm{c}}\end{array}$ & $\begin{array}{c}25,52 \pm \\
1,25^{\mathrm{b}}\end{array}$ & $\begin{array}{c}162,16 \pm \\
8,6^{\mathrm{b}}\end{array}$ & $\begin{array}{c}244,59 \pm \\
3,18^{\mathrm{c}}\end{array}$ \\
\hline Fracción & $66,41 \pm$ & $529,80 \pm$ & $66,54 \pm$ & $444,38 \pm$ & $406,86 \pm$ \\
\hline Metanólica & $1,67^{\mathrm{d}}$ & $14,3^{\mathrm{d}}$ & $3,07^{\mathrm{c}}$ & $11,31^{\mathrm{c}}$ & $24,58^{\mathrm{d}}$ \\
\hline Valor $p$ & $<0,05$ & $<0,05$ & $<0,05$ & $<0,05$ & $<0,05$ \\
\hline
\end{tabular}

En la tabla 1 se muestra el rendimiento del extracto metanólico de las hojas de $S$. rufescens DC., y de cada una sus fracciones. Se obtuvo un rendimiento de $40 \%$ de extracto metanólico, un porcentaje muy alto, posiblemente porque hemos utilizado metanol sin dilución y por haber realizado una extracción dinámica por agotamiento $(4$ x $500 \mathrm{~mL})$; y no una maceración simple. Mientras que en las fracciones, la fracción de diclorometano mostró el mayor porcentaje (39,79 $\%$ ), seguido de las fracciones metanólica (27,51\%), acetato de etilo (18,52\%) y $n$ - hexano $(14,18 \%)$, respectivamente. El fraccionamiento del extracto metanólico permitió separar los compuestos químicos presentes en el extracto de acuerdo a su polaridad, en el cual la fracción de diclorometano tuvo mayor porcentaje, mientras que la fracción de $n$ - hexano tuvo menor porcentaje. Estas diferencias entre las fracciones se deben a la naturaleza y polaridad de los compuestos presentes en cada uno de las fracciones.

En estudios realizados con especies del género Senecio se han utilizado diferentes solventes para realizar la extracción de compuestos bioactivos a partir de sus partes aéreas, en el caso de $S$. clivicolus Wedd. se utilizó etanol al $96 \%{ }^{4}$, en $S$. scandens Buch.-Ham. etanol al $80 \%{ }^{12}$ y en $S$. glaucus subsp coronopifolius (Maire) C. Alexander. metanol al 70 \% ${ }^{13}$, con 27,06 \%; 6,25 \% y $7,5 \%$ de rendimiento, respectivamente. En S. scandens Buch.-Ham. ${ }^{12}$ y en S. glaucus subsp coronopifolius (Maire) C. Alexander. ${ }^{13}$, se utilizó maceración simple por agotamiento por siete días, mientras que, en S. cluvicolus Wedd. ${ }^{4}$ se utilizó maceración dinámica obteniéndose mejores resultados, pero que es inferior al nuestro.

La literatura reporta que los terpenos, tales como monoterpenos, sesquiterpenos, diterpenos y triterpenos, están presentes en cantidades significativas en especies del género Senecio ${ }^{2}$, 
compuestos que pueden ser solubilizados en diclorometano y posiblemente a esto se deba el porcentaje elevado de esta fracción en $S$. rufescens DC. Asimismo, se ha reportado en otras especies del género Senecio, el fraccionamiento por partición líquido - líquido con solventes de polaridad creciente. En el caso de S. glaucus L., el extracto etanólico se fraccionó con $n-$ hexano, cloroformo y $n$-butanol, obteniéndose $13,33 \%, 21,76 \%$ y $36,67 \%$ de rendimiento ${ }^{3}$, mientras que en $S$. clivicolus Wedd. el extracto etanólico al $96 \%$ fue fraccionado con $n-$ hexano, cloroformo, acetato de etilo y n - butanol, obteniéndose 8,61 $\pm 0,75 \% ; 63,39 \pm 5,23$ $\% ; 6,87 \pm 0,39 \%$ y $13,53 \pm 0,95 \%$ de rendimiento4, respectivamente. Nuestros resultados se acercan a este último, en el cual, la fracción de cloroformo tuvo el mayor porcentaje y la de $\mathrm{n}$ - hexano el menor porcentaje.

Por otro lado, en la tabla 2 presentamos el contenido de fenoles totales, flavonoides y flavonoles presentes en el extracto metanólico de las hojas de $S$. rufescens DC. y de sus fracciones. Se observa que estos varían desde el extracto metanólico $(64,5 \pm 1,17 \mathrm{mg}$ GAE/g de extracto; 36,55 $\pm 1,91 \mathrm{mg} \mathrm{QE} / \mathrm{g}$ de extracto y 10,58 \pm 0,85 mg QE/g de extracto, respectivamente), y en cada una de las fracciones en función de su polaridad. La fracción de acetato de etilo $(74,46 \pm 1,6 \mathrm{mg}$ GAE/g de extracto; $28,06 \pm 1,1 \mathrm{mg}$ QE/g de extracto y 2,92 $\pm 0,23 \mathrm{mg}$ QE/g de extracto, respectivamente) y la fracción metanólica $(149,81 \pm$ $5,02 \mathrm{mg} \mathrm{GAE} / \mathrm{g}$ de extracto; 47,33 $\pm 2,27 \mathrm{mg}$ QE/g de extracto y 14,34 $\pm 0,69 \mathrm{mg} \mathrm{QE} / \mathrm{g}$ de extracto, respectivamente), mostraron el mayor contenido de fenoles totales, flavonoides y flavonoles. La fracción metanólica tiene los valores más altos de los tres compuestos, posiblemente porque están unidos a restos azucarados que les proporciona mayor polaridad y por ende solubilidad en solventes más polares. Las diferencias estadísticas entre el contenido de estos tres compuestos en el extracto metanólico y en cada una de sus fracciones fueron significativas $(p<0,05)$.

Existen reportes en la literatura sobre el contenido de fenoles totales en el género Senecio, cuyos rangos varían desde 2,46 $\pm 0,11 \mathrm{mg} \mathrm{GAE} / \mathrm{g}$ de extracto en el extracto acuoso de $S$. anteuphorbium (L) Sch.Bip., ${ }^{14}$ hasta 170,11 $\pm 1,49 \mathrm{mg}$ GAE/g de extracto en la fracción de acetato de etilo de $S$. clivicolus Wedd. ${ }^{4}$ de sus partes aéreas, respectivamente En nuestro estudio, hemos hallado que la fracción metanólica del extracto metanólico de las partes aéreas de $S$. rufescens DC. tuvo un contenido relativamente alto de fenoles totales $(149,81 \pm$ $5,02 \mathrm{mg} \mathrm{GAE} / \mathrm{g}$ de extracto).

En el caso de los flavonoides, también la literatura reporta un contenido variable que va desde 2,5 $\pm 0,2 \mathrm{mg} \mathrm{EQ} / \mathrm{g}$ de hoja seca en una infusión de hojas de $S$. viridis Phil., hasta 35,9 $\pm 0,17$ $\mathrm{mg}$ EQ/g de extracto del extracto metanólico de hojas de $S$. glaucus subsp coronopifolius (Maire) C. Alexander. ${ }^{13}$. En nuestro estudio obtuvimos valores de 36,55 $\pm 1,91 ; 28,06 \pm 1,1$ y 47,33 $\pm 2,27 \mathrm{mg}$ EQ/g de extracto, del extracto metanólico y de las fracciones de acetato de etilo y metanólica, respectivamente; demostrándose que $S$. rufescens DC., posee un contenido significativo de flavonoides respecto a otras especies del género Senecio reportada en la literatura. Asimismo, determinamos la relación entre el contenido de flavonoides y fenoles totales en las fracciones de diclorometano, acetato de etilo y metanólica, en la cual los flavonoides representaron aproximadamente un tercio del contenido de fenoles totales en dichas fracciones. 
Nosotros también hacemos el primer reporte del contenido de flavonoles en especies del género Senecio. En nuestro estudio, el contenido de flavonoles en el extracto metanólico y en las fracciones de diclorometano, acetato de etilo y metanólica fueron $10,58 \pm 0,85 ; 6,48$ $\pm 0,34 ; 2,92 \pm 0,23 ; 14,34 \pm 0,69 \mathrm{mg} \mathrm{QE} /$ de extracto, respectivamente. Estos representaron también aproximadamente un tercio del contenido de flavonoides en las fracciones de diclorometano y metanólica, respectivamente. En el género Senecio es recurrente la presencia de flavonoles como kaempferol, quercetina, myricetina y fisetina, tanto como agliconas libres y sus derivados glicosilados $2,4,12$.

Esta diferencia entre el contenido de fenoles totales y de flavonoides en el género Senecio, nos permite asumir que está cubierta por otros compuestos fenólicos, tales como ácidos fenólicos derivados del ácido clorogénico y de ácidos dicafeoilquínicos, entre otros compuestos fenólicos, quienes también poseen la habilidad para neutralizar radicales libres ${ }^{4}$.

Mientras que en la tabla 3 mostramos los resultados de la capacidad antioxidante del extracto y de sus fracciones de las partes aéreas de $S$. rufescens DC. En la cual, la fracción metanólica tiene la más alta capacidad antioxidante (DPPH: 66,41 $\pm 1,67 \%$; 529,80 $\pm 14,30 \mu$ moles ET/g de extracto; ABTS: 66,54 $\pm 3,07 \%$; 444,38 $\pm 11,31 \mu$ moles ET/g de extracto; y FRAP: $406,86 \pm 24,58 \mu$ moles ET/g de extracto, respectivamente), seguido del extracto metanólico $(13,61 \pm 0,84 \% ; 76,97 \pm 7,17 \mu$ moles ET/g de extracto; ABTS: $27 \pm 1,57 \% ; 172,38 \pm 10,78$ $\mu$ moles ET/g de extracto; y FRAP: $188,68 \pm 2,76 \mu$ moles ET/g de extracto, respectivamente). Asimismo, hallamos diferencias significativas entre la capacidad antioxidante del extracto metanólico y de cada una de las fracciones para los ensayos de DPPH, ABTS y FRAP $(p<0,05)$, respectivamente.

Los ensayos de DPPH y ABTS, son ensayos que miden la capacidad de secuestramiento de radical libre. En el caso del ensayo del $\mathrm{DPPH}^{9}$, este se realiza en medio metanólico, por tanto, comprende antioxidantes lipofílicos e hidrofílicos presentes en el extracto y en sus fracciones, en el cual se mide la decoloración del reactivo de color violeta a amarillo a 517 nm. Mientras que en el caso del ABTS $^{9}$, este se desarrolla en medio acuoso, por tanto, se aborda principalmente a los antioxidantes hidrofílicos, en el cual el catión $\mathrm{ABTS}^{\bullet+}$ formado en el medio de reacción, se decolora de verde azulado intenso a verde azulado pálido, el cual se mide a $734 \mathrm{~nm}$. Por otro lado, el ensayo del FRAP ${ }^{9}$ se fundamenta en la capacidad reductora del catión $\mathrm{Fe}^{3+}$ presente como un complejo formado con TPTZ que es de color violáceo a $\mathrm{Fe}^{2+}$, resultando en una intensificación del color violáceo, por ende, se incrementa su absorbancia cuando es leída a $593 \mathrm{~nm}$. Por lo tanto, la decoloración de los radicales libres DPPH y ABTS se debe a la presencia de antioxidantes capaces de donar un protón a dichos radicales libres y en el caso del ensayo FRAP, se debe a la capacidad reductora del catión $\mathrm{Fe}^{3+}$ por parte de grupos hidróxilos. Estos compuestos, están presentes en el extracto metanólico de las hojas de S. rufescens DC., y de sus fracciones, principalmente como compuestos fenólicos ${ }^{15}$, tal como ha sido mostrado en la tabla 2.

Sólo existe un reporte en el género Senecio, en el cual, se evaluó la capacidad antioxidante utilizando los ensayos de DPPH, ABTS y FRAP, respectivamente. En dicho reporte, la fracción 
de acetato de etilo (DPPH: 317,53 \pm 5,81 mg ET/g de extracto; ABTS: 409,53 \pm 9,53 mg ET/g de extracto; y FRAP: 507,66 $\pm 5,26 \mathrm{mg}$ ET/g de extracto, respectivamente) del extracto etanólico de las partes aéreas de $S$. clivicolus Wedd., tuvo mayor capacidad antioxidante que la fracción butanólica (DPPH: 119,54 $\pm 6,71 \mathrm{mg}$ ET/g de extracto; ABTS: 208,37 $\pm 3,21 \mathrm{mg}$ ET/g de extracto; y FRAP: $184,18 \pm 4,59 \mathrm{mg}$ ET/g de extracto, respectivamente) ${ }^{4}$. En nuestro estudio, con el ensayo de DPPH se obtuvieron valores más altos que con el ensayo FRAP, mientras que, en S. clivicolus Wedd., se obtuvieron resultados opuestos. Asimismo, nosotros obtuvimos una mayor capacidad antioxidante en la fracción metanólica obtenida a partir del extracto metanólico, mientras que en $S$. clivicolus Weed., se obtuvo la mayor actividad en la fracción de acetato de etilo del extracto etanólico. Esta diferencia se debe posiblemente a la naturaleza y concentración de los compuestos con capacidad antioxidante presentes en dichas fracciones y, asimismo, al origen de la muestra, puesto que $S$. clivicolus Wedd., fue colectada en el departamento de Potosí (Bolivia) a una altitud de $3750 \mathrm{msnm}$, mientras que nuestra muestra de $S$. rufescens DC., fue colectada a $4756 \mathrm{msnm}$.

En la literatura se reporta el caso del estudio de la actividad antioxidante del fruto de un cultivar de Vaccicium corymbosum L. y de 14 cultivares de Vaccicium ashei Reade "arandano", en el cual, el rango de los resultados del ensayo de DPPH (1014,20 a 2055,06 $\mu$ moles ET/100g) fueron superiores al del ensayo de FRAP $(699,78 \text { a 1740,25 } \mu \text { moles ET/100g })^{16}$, respectivamente. Por tanto, si bien estos resultados corresponden a otras especies, son compatibles con nuestro resultado, el de obtener valores más altos para el ensayo de DPPH respecto al de FRAP.

En consecuencia, con los resultados obtenidos podemos afirmar que el extracto metanolico y las fracciones de acetato de etilo y metanólica de las partes aéreas de $S$. rufescen DC., tienen compuestos con alta capacidad antioxidante, en el cual, los responsables de dicha actividad serían los compuestos fenólicos conformados por ácidos fenólicos y flavonoides principalmente, que pueden estar presentes ya sea como compuestos libres o agliconas y también como glicósidos, que son más solubles en solventes más polares como el metanol, destacando este último en nuestro estudio, por mostrar mayor capacidad antioxidante. $S$. clivicolus Wedd. ${ }^{4}$ y S. scandens Buch.-Ham. ${ }^{12}$, se caracterizan por presentar ácidos fenólicos y derivados del ácido dicafeoilquínicos, así como flavonoles y sus derivados glicosilados, los cuales poseen una gran capacidad antioxidante.

Finalmente, se hace necesario aislar los compuestos fenólicos en S. rufescens DC., y determinar su estructura química para explicar mejor su capacidad antioxidante y realizar otros ensayos relacionados con sus propiedades biológicas.

\section{CONCLUSIONES}

En conclusión, reportamos el contenido de fenoles totales, flavonoides y flavonoles; y su capacidad antioxidante utilizando los ensayos de DPPH, ABTS y FRAP del extracto metanólico y de sus fracciones, obtenidas a partir de las hojas de S. rufescens DC., resaltando 
el alto contenido de compuestos fenólicos y la alta capacidad antioxidante de la fracción metanólica en los modelos ensayados.

\section{AGRADECIMIENTO}

Al laboratorio de Farmacognosia de la Facultad de Ciencias de la Salud de la Universidad Nacional de San Cristóbal de Huamanga, por las facilidades para la realización de la presente investigación.

\section{REFERENCIAS BIBLIOGRÁFICAS}

1. Beltrán H, Roque J. El género Senecio L. (Asteraceae-Senecioneae) en el departamento de Lima, Perú. Arnaldoa. 2015;22(2):395-412.

2. Yang Y, Zhao L, Wang Y-F, Chang M-L, Huo C-H, Gu Y-C, et al. Chemical and pharmacological research on the plants from Genus Senecio. Chem Biodivers. 2011;8(1):13-72.

3. Alqahtani AS, Herqash RN, Noman OM, Nasr FA, Alyhya N, Anazi SH, et al. In vitro antioxidant, cytotoxic activities, and phenolic profile of Senecio glaucus from Saudi Arabia. Evid Based Complement Altern Med. 2020;9. doi:10.1155/2020/8875430

4. Faraone I, Rai DK, Chiummiento L, Fernandez E, Choudhary A, Prinzo F, et al. Antioxidant activity and phytochemical characterization of Senecio clivicolus Wedd. Molecules. 2018;23(10):1-17.

5. Singh R, Singh P, Sati N, Sati OP. Antioxidant activity of Senecio amplexicaulis Kunth. extracts. World J Pharm Sci. 2015;3(3):600-604.

6. Pietrellini F. Las Plantas Medicinales en un piso alto y mesoandino. Estudio etnobotánico en la zona de Puquio (Ayacucho). Huamanga - Perú: Graficenter Perú EIRL; 2007. 491$492 \mathrm{p}$.

7. Baskar V, Venkatesh R, Ramalingam S. Flavonoids (Antioxidants Systems) in Higher Plants and Their Response to Stresses. In: Gupta DK, Palma JM, Corpas FJ, editors. Antioxidants and Antioxidant Enzymes in Higher Plants. Cham (Switzerland): Springer International Publishing AG; 2018. p. 253-268.

8. Soriano M, Bonilla P, Arroyo Acevedo J, Pereyra S. Actividad cicatrizante tópica de los metabolitos secundarios en el extracto etanólico de hojas de Senecio culcitoides Weed. Folia Dermatol Peru. 2004;15(3):155-159.

9. Thaipong K, Boonprakob U, Crosby K, Cisneros-Zevallos L, Hawkins Byrne D. Comparison of ABTS, DPPH, FRAP, and ORAC assays for estimating antioxidant activity from guava fruit extracts. J Food Compos Anal. 2006;19(6-7):669-675.

10. Zhishen J, Mengcheng T, Jianming W. The determination of flavonoids contents in mulberry and their scavenging effects on superoxide radicals. Food Chem. 1999;64:555559.

11. Miliauskas G, Venskutonis PR, Van Beek TA. Screening of radical scavenging activity of some medicinal and aromatic plant extracts. Food Chem. 2004;85(2):231-237. 
12. Tan D-P, Chou G-X, Wang Z-T. Phenolic compounds from Senecio scandens. Biochem Syst Ecol. 2010 Feb;38(1):122-124.

13. Shaza M. Phytochemical and Biological Study of Senecio glaucus subsp. coronopifolius (Maire) C. Alexander Growing in Egypt. J Pharm Sci. 2015;52:283-298.

14. Lahlou F, Hmimid F, Loutfi M, Bourhim N. Antioxidant Activity Phenolics Flavonoids and Proanthocyanidins Content of Senecio anteuphorbium. Int J Biochem Res Rev. 2014;4(6):550-558.

15. Shah P, Modi HA. Comparative Study of DPPH, ABTS and FRAP Assays for Determination of Antioxidant Activity. Int J Res Appl Sci Eng Technol. 2015;3(98):636641.

16. Rodrigues E, Poerner N, Rockenbach II, Gonzaga LV, Mendes CR, Fett R. Phenolic compounds and antioxidant activity of blueberry cultivars grown in Brazil. Food Sci Technol. 2011;31(4):911-917. 